\title{
Planejamento Familiar em Três Poços, Volta Redonda, Estado do Rio de Ja- neiro, Brasil.
}

\section{Family Planning In Três Poços, Volta Redonda, State Of The Rio de Janeiro, Brasil.}

Artigo

Original

\section{Original}

Paper

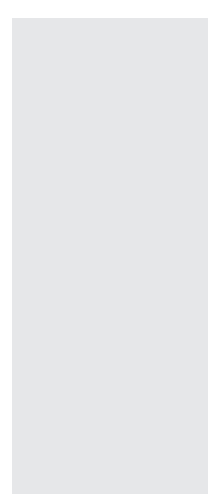

Submetido

em: 13/02/08

\author{
Marcos Nascimento e Silva ${ }^{1}$ \\ Sylvio Costa Junior ${ }^{1}$ \\ Monique Barreiros Vieira ${ }^{2}$ \\ Marcelo Genestra ${ }^{3}$ \\ Márcia D. Trindade Cardoso ${ }^{4}$
}

Palavras-chaves:

Planejamento

Familiar

Anticoncepção

Programa de

Saúde da Família

\section{Revisado}

em: 18/03/08

Abstract

Key words:

We developed a quantitative study in the Family Health care Program (PSF) in the neighborhood of Três Poços e Volta Redonda, State of Rio de Janeiro, Brazil. The study evaluates the acceptability of the contraception among users, to identify, in agreement with the participants' perception, facilitators and barriers for the use of the methods. Data collection and analyses of records of the family's program, accomplished in PSF. The participants showed favorable to disseminate the information, provision and use of the contraceptive methods. It was verified that significant barriers still exist for the acceptance within the community of Três Poços, related to the use of the several anti-conception methods extolled in Brazil. The methods are arranged for the unique system of Health (SUS), in free and universal way for the users. It is essential to have qualified health professionals to provide information and stimulate the family planning.

Family Planning

Anti-conception

Family Health

Care Program

\section{Introdução}

A contracepção talvez seja a maior preocupação das mulheres em idade fértil em todo o planeta. Mesmo em países industrializados, como os Estados Unidos, por exemplo, a taxa de gravidez não planejada gira em torno de $50 \%$. Esta preocupação deve ser ainda maior entre as mulheres que residem em países em desenvolvimento como o Brasil; onde,

${ }^{1}$ Discentes do Curso de Pós-graduação em Saúde da Família/UniFOA

${ }^{2}$ Discente do Curso de Medicina/UniFOA

${ }^{3}$ Docente dos Cursos de Graduação em Medicina e Odontologia e do Programa de Pós-graduação/UniFOA

${ }^{4}$ Docente dos Cursos de Graduação em Medicina e do Programa de Pós-graduação/UniFOA 
segundo estimativas, uma mulher tem uma chance 200 vezes maior de morrer durante a gravidez se comparado com um país desenvolvido (REZENDE et al., 1999).

O planejamento familiar é definido pela Lei 9263 de 12101/1996 como um "conjunto de ações de regulação da fecundidade que garanta direitos iguais de constituição, limitação ou aumento da prole pela mulher, pelo homem ou pelo casal". Isto é diferente de controle de natalidade, que é a situação onde o Estado intervém ativamente no sentido de controlar a taxa de natalidade de uma população, impedindo seu livre crescimento.

O Ministério da Saúde disponibiliza diversos métodos para a população como condom masculino e feminino, diafragma, esterilização cirúrgica, minipílula, dispositivo intrauterino (DIU), anticoncepcional oral (ACO) e injetáveis e espermicida. Existem também os chamados métodos de comportamento, como ritmo, Billings, temperatura basal, sinto-térmico e coito interrompido.

\subsection{Métodos de Barreiras}

A camisinha ou condom masculino de látex é uma capa feita para cobrir e se ajustar ao pênis ereto do homem e formar uma barreira física entre o pênis e vagina. Alguns são lubrificados com silicone ou lubrificantes à base de água, e alguns são revestidos com espermicidas além do lubrificante. Está disponível em uma grande variedade de tamanhos, formas, cores e texturas.

Existe também o condom masculino de plástico, que é mais forte e fino do que o condom de látex. É mais resistente à luz e ao calor do que o condom de látex. Permite maior sensibilidade durante o ato sexual. Pode ser usado com lubrificantes à base de óleo. $\mathrm{O}$ grau de proteção contra doenças sexualmente transmissíveis (DST) é semelhante ao condom de látex. Vários tipos de condom de plástico estão em estudo, e ainda não são disponíveis no Brasil.

O condom feminino é uma bolsa de plástico leve, frouxa, que se adapta à vagina e protege o colo do útero, a vagina e a genitália externa. A bolsa possui um anel leve e flexível em cada extremidade. A extremidade fechada do preservativo feminino é inserida até o fundo da vagina. $\mathrm{O}$ anel aberto permanece do lado de fora da vagina após a inserção, protegendo os lábios e a base do pênis durante o ato sexual. O produto é pré-lubrificado e serve para ser utilizado apenas uma vez.

O diafragma é um método vaginal de anticoncepção, que consiste em um capuz macio de borracha côncavo com borda flexível, que cobre o colo uterino. São disponíveis os modelos de fabricação nacional e importado, em diferentes numerações. Deve ser introduzido na vagina, antes do coito, a fim de impedir que o esperma tenha acesso ao útero e trompas, cujo método que deve ser utilizado junto com um espermicida para garantir maior eficácia (KALCKMANN, 1995).

O Capuz Cervical é bem menor que o diafragma, varia aproximadamente entre $22 \mathrm{e}$ $31 \mathrm{~mm}$ de diâmetro. O capuz é preso ao colo do útero por ajuste e pressão negativa, a cúpula do capuz é voltada para fora e preenchida em um terço por espermicida, pode permanecer por $72 \mathrm{~h}$. Até que se tenha prática no ajuste deve-se utilizar outro meio contraceptivo concomitantemente. O capuz cervical é menos eficaz que o diafragma.

\subsection{Métodos Comportamentais}

A tabelinha ou calendário fundamenta-se em calcular o início e o fim do período fértil e somente é adequado para mulheres com ciclo menstrual regular e que conheçam o próprio corpo para estar atenta às mudanças que ocorrem no período de maior fertilidade. A paciente deve medir a temperatura oral, durante 5 minutos, pela manhã (após repouso de no mínimo 5 horas) antes de comer ou fazer qualquer esforço, e anotar os resultados durante dois ou mais ciclos menstruais. Esse procedimento deve ser realizado desde o primeiro dia da menstruação até o dia em que a temperatura se elevar por três dias consecutivos.

Depois de estabelecer qual é a sua variação normal, e o padrão de aumento, poderá usar a informação, evitando relações sexuais no período fértil.

O método do muco cervical (Billing) baseia-se na identificação do período fértil 
pelas modificações cíclicas do muco cervical, observado no auto-exame e pela sensação por ele provocada na vagina e vulva. A observação da ausência ou presença do fluxo mucoso deve ser diária. O muco cervical aparece cerca de 2 à 3 dias depois da menstruação, e inicialmente é pouco consistente. Logo antes da ovulação, ele atinge o chamado "pico", sob a influência do estrogênio, o muco aumenta em quantidade e torna-se progressivamente mais escorregadio e elástico, em seguida, o muco torna-se escasso e seco, sob a influência da progesterona, até o início da próxima menstruação (WEREBE, 1985).

O coito interrompido baseia-se na capacidade do homem em pressentir a iminência da ejaculação e, neste momento, retirar o pênis da vagina e da genitália externa. Ainda é um método muito importante de controle da fertilidade nos países pobres, é de disponibilidade imediata e sem custo. O risco de DST, teoricamente, deve ser reduzido. A taxa de fracasso é de $6,7 \%$ de mulheres-ano, o líquido pré-ejaculatório pode conter espermatozóides vivos, pode levar à disfunção sexual do casal. O método sitotérmico é uma combinação dos métodos do calendário e do muco. Neste método o primeiro dia de abstinência é previsto pelo calendário, subtraindo-se 21 da duração do menor ciclo menstrual nos últimos seis meses, ou é detectado o primeiro dia de muco, o que acontecer primeiro. $\mathrm{O}$ final do período fértil é previsto pelo uso da temperatura corporal basal.

\subsection{Dispositivos Intra-Uterinos}

O dispositivo intra-uterino (DIU) é um objeto pequeno de plástico flexível, freqüentemente com revestimento ou fios de cobre. O dispositivo é inserido no útero da mulher através da vagina. É conhecido também por suas características específicas: o DIU com cobre -TCu 380A e MLCu-375 (Multiload); o DIU que libera progestágeno - LNG-20 (Mirena); e o DIU inerte, não medicado - alça de Lippes - que atualmente não está disponível.

O DIU atua impedindo a fecundação; aparentemente, torna mais difícil a passagem do espermatozóide pelo trato reprodutivo feminino, reduzindo a possibilidade de ferti- lização do óvulo. Também é possível que o DIU previna a implantação do ovo fertilizado na parede uterina. Para a Organização Mundial da Saúde, o DIU interfere nas diferentes etapas do processo reprodutivo que ocorrem previamente à fertilização (REZENDE et al., 1999).

\subsection{Contracepção Hormonal}

O anticoncepcional oral (ACO) contém um estrogênio e um progestogênio, em diferentes doses e esquemas posológicos. As pílulas monofásicas são as mais comuns, encontradas em embalagens de 21 ou 22 comprimidos ativos. A grande maioria tem 21 comprimidos. Todos os comprimidos ativos têm a mesma composição e dose. Para algumas marcas, as embalagens contêm, além das pílulas ativas, 6 ou 7 de placebo para completar 28 comprimidos. As pílulas bifásicas contêm dois tipos de comprimidos ativos, de diferentes cores, com os mesmos hormônios em proporções diferentes. Devem ser tomados na ordem indicada na embalagem. As pílulas trifásicas contêm três tipos de comprimidos ativos, de diferentes cores, com os mesmos hormônios em proporções diferentes. Devem ser tomados na ordem indicada na embalagem. A pílula para uso vaginal é monofásica para uso por via vaginal, contendo 21 comprimidos ativos na embalagem.

As pílulas seqüenciais não são recomendáveis para anticoncepção; praticamente estão sendo abandonadas. As que ainda existem são utilizadas para controlar o ciclo, especialmente no período de climatério. Contêm dois tipos de comprimidos ativos, uns (habitualmente 11) só com estrogênio e outros (habitualmente 10), contendo estrogênio e progestogênio.

Os anticoncepcionais orais de progestogênio contêm uma dose muito baixa de um tipo de hormônio, o progestogênio, em torno da metade a um décimo da quantidade de progestogênio dos anticoncepcionais orais combinados. Eles não contêm estrogênio. Os anticoncepcionais orais de progestogênio também são conhecidos como pílulas progestínicas (PP) e minipílula. São os anticoncepcionais orais mais apropriados para a mulher que amamenta. Porém, mulheres que não estão amamentando também podem usá-los.

$\mathrm{O}$ acetato de medroxiprogesterona é 
um método anticoncepcional injetável apenas de progestogênio, que é um composto semelhante ao produzido pelo organismo feminino, e liberado lentamente na circulação sanguínea. Impede a ovulação e espessa o muco cervical, dificultando a passagem do espermatozóide através do canal cervical.

Os anticoncepcionais orais devem ser utilizados de maneira criteriosa, seguindo a posologia de cada fabricante. O seu uso de maneira errônea, tem levado a inúmeras gravidezes indesejadas, prejudicando o planejamento familiar (LEITE, 1991).

\subsection{Contracepção Cirurgica}

A esterilização feminina é um método anticoncepcional permanente para mulheres que não desejam ter mais filhos. $\mathrm{O}$ método requer um procedimento cirúrgico, simples e seguro. A esterilização feminina é também conhecida como laqueadura tubária, ligadura tubária, ligadura de trompas e anticoncepção cirúrgica voluntária. Pode ser realizada através da salpingectomia parcial, através de anéis que são colocados em volta de uma pequena alça de trompa com um aplicador especial, eletrocoagulação (fulguração) onde utiliza corrente elétrica para queimar uma pequena porção das trompas ou através de grampos que causa menor lesão nas trompas.

A vasectomia oferece anticoncepção permanente para homens que não desejam ter mais filhos. É um procedimento cirúrgico simples, seguro e rápido. Pode ser feito em uma clínica ou consultório, desde que se observem os procedimentos adequados para prevenção de infecções. Não afeta o desempenho sexual. É também conhecida como esterilização masculina e anticoncepção cirúrgica masculina (GALASTRO,1997).

A técnica básica usada para oclusão do ducto deferente consiste em cortá-lo e fechar as extremidades através de ligadura, eletrocoagulação ou colocação de grampos (esta última não é de utilização comum).

\section{Casuística e Métodos}

Realizou-se um estudo quantitativo descritivo retrospectivo no Programa de Saúde da Família (PSF) no bairro Três Poços, na cidade de Volta Redonda, Estado do Rio de Janeiro, Brasil, no período de agosto à setembro de 2007. Como estratégia de ação foi adotado um método estruturado através de levantamento de fichas do programa de planejamento familiar (Anexo 1). O público alvo incluiu todos os pacientes cobertos pelo PSF/Três Poços cadastrados no programa de planejamento familiar. Inicialmente, a amostra era constituída de 101 fichas de pacientes, sendo que desta população, 61 pessoas concluíram o planejamento familiar e 40 desistiram do programa. Desta forma, o universo real de amostra pesquisada foi efetivamente de 61 fichas. Os critérios de inclusão utilizados no estudo levaram em consideração todos os participantes cadastrados regularmente no programa de planejamento familiar; os critérios de exclusão incluíram o descarte de fichas que, por algum motivo, não foram preenchidas corretamente. Foram respeitados os aspectos éticos em comformidade com a Resolução 196/96 do Conselho Nacional de Saúde.

\section{Resultados e Discussão}

A concepção é o resultado natural do intercurso sexual entre homem e mulher. Partindo dessa premissa, espera-se que a anticoncepção seja um fenômeno, também, por natureza, resultante da conjugação de esforços dos parceiros igualmente envolvidos nessa relação. Entretanto, a cultura patriarcal em que vivemos confinou a mulher no âmbito da maternidade, do lar e das tarefas internas familiares. O mundo externo foi considerado de âmbito masculino. Nos países latino-americanos, além da cultura patriarcal, o machismo está presente como forma de dominação do homem sobre a mulher (SCHIAVO, 1987).

Este trabalho oferece uma contribuição aos profissionais das unidades de saúde que trabalham com a contracepção. Existe um monólogo permanente sobre os rumos da política contraceptiva a se estende até a presente década, com acréscimo de contribuições de outros profissionais, suas dúvidas e críticas assemelhadas. A nossa pretensão é aqui iniciar a discussão dos elementos: significados da contracepção, política contraceptiva e representações sociais que estão presentes nas ações de contracepção de modo a facilitar o estabelecimento da interface 
com os profissionais que desenvolvem trabalho nesta área.

Os gráficos elaborados ilustram a realidade deste universo. No gráfico A-1 evidenciamos que os pacientes que mais fazem uso de condom masculino encontram-se na população de 21-25 anos e o uso vai caindo progressivamente até atingir a faixa etária com menor percentual de uso, localizada entre os 40-50 anos, refletindo que aqueles que se encontram entre os adultos jovens e com vida sexual ativa tem o percentual de uso de condom masculino que chega aos 90\% (Gráfico A-10), enquanto que o grupo com parceira fixa o uso é o menor (Gráfico A-5). Deste grupo de homens que utilizam este método anticonceptivo a instrução majoritária se encontra entre os que cursaram o segundo grau (Gráfico A-2). A renda, influenciada pelo grau de instrução, é majoritariamente de 1-3 salários mínimos (Gráfico A-4). A prevalência do uso de contraceptivo, no Brasil, é elevada e a taxa de fecundidade total vem diminuindo. No entanto, ainda há um percentual significativo de gravidez indesejada, abortos provocados e mulheres que não querem mais ter filhos ou querem tê-los mais tarde, porém não estão usando métodos contraceptivos (STEPHAN-SOUZA, 1995). O tempo de uso deste método é variável de 6 meses à 10 anos (Gráfico A-13), mas mais de 50\% desta população faz uso contínuo (Gráfico A-14), mostrando que a penetração da informação tem tido uma boa aceitação. Em nosso universo de estudo $60 \%$ tem vida sexual estável com esposa ou companheira e a maioria já possui mais de um filho (Gráfico A-18).

Neste PSF somente duas pessoas fazem uso de diafragma (Gráfico B-1). Ambas começaram a vida sexual cedo (Gráfico B-7), tem um bom conhecimento sobre anticoncepção (Gráfico B-8). Uma paciente já é mãe a outra não (Gráfico B-18). Uma paciente faz uso contínuo a mais de um ano a outra paciente não (Gráfico B-13). O DIU é usado principalmente por mulheres de 25 à 35 anos (Gráfico C-1). A instrução é de segundo grau completo (Gráfico C-2), com renda de 1 à 3 salários mínimos (Gráfico C-4). Foram encontradas duas pacientes que utilizam o DIU e uma é casada e outra é solteira (Gráfico C-5). Ambas conhecem vários métodos anticonceptivo (Gráfico C-8), já usaram pílula e condom masculino (Gráfico C-9), mas preferiram o DIU.

Gráfico A: CONDOM MASCULINO
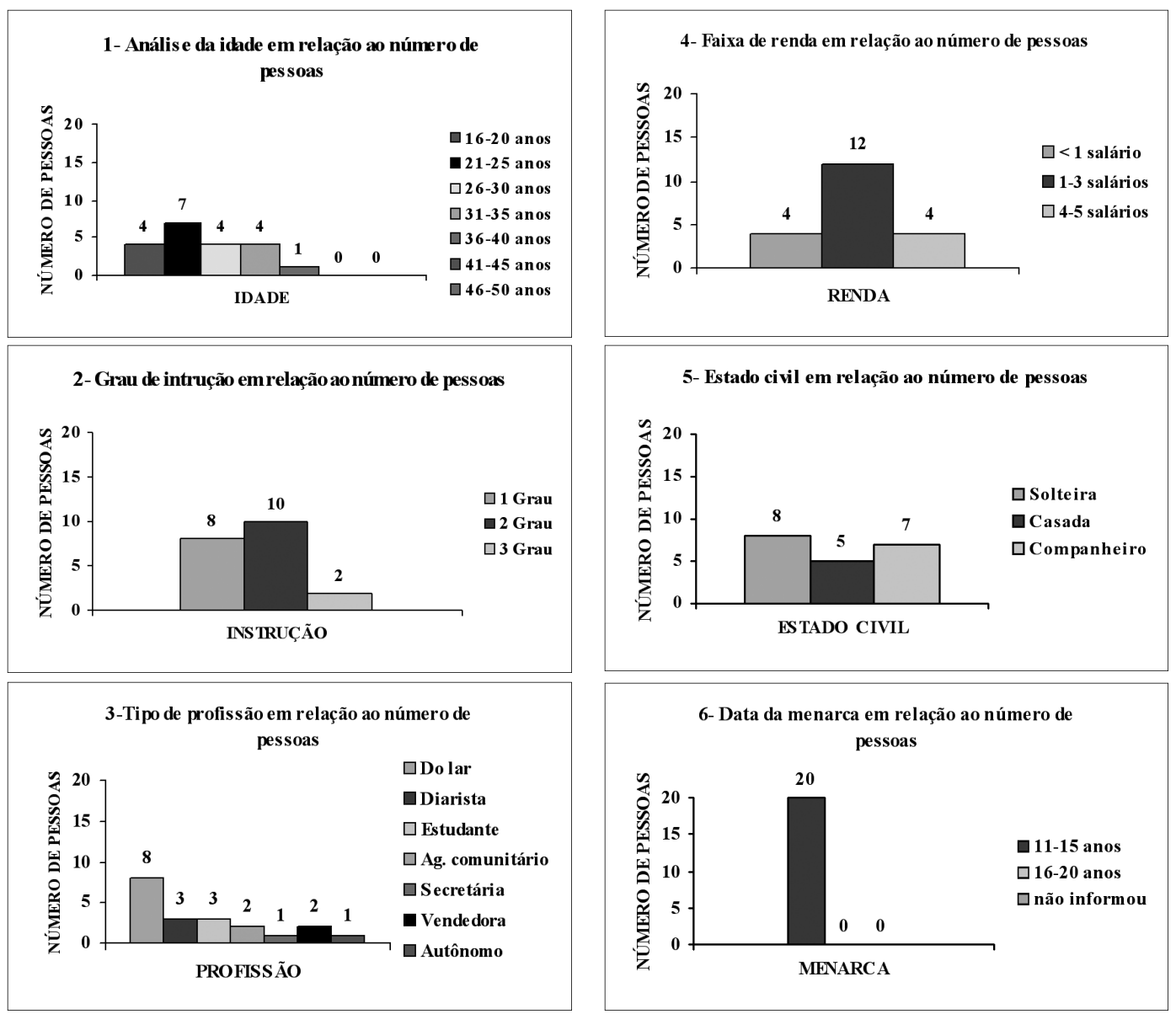

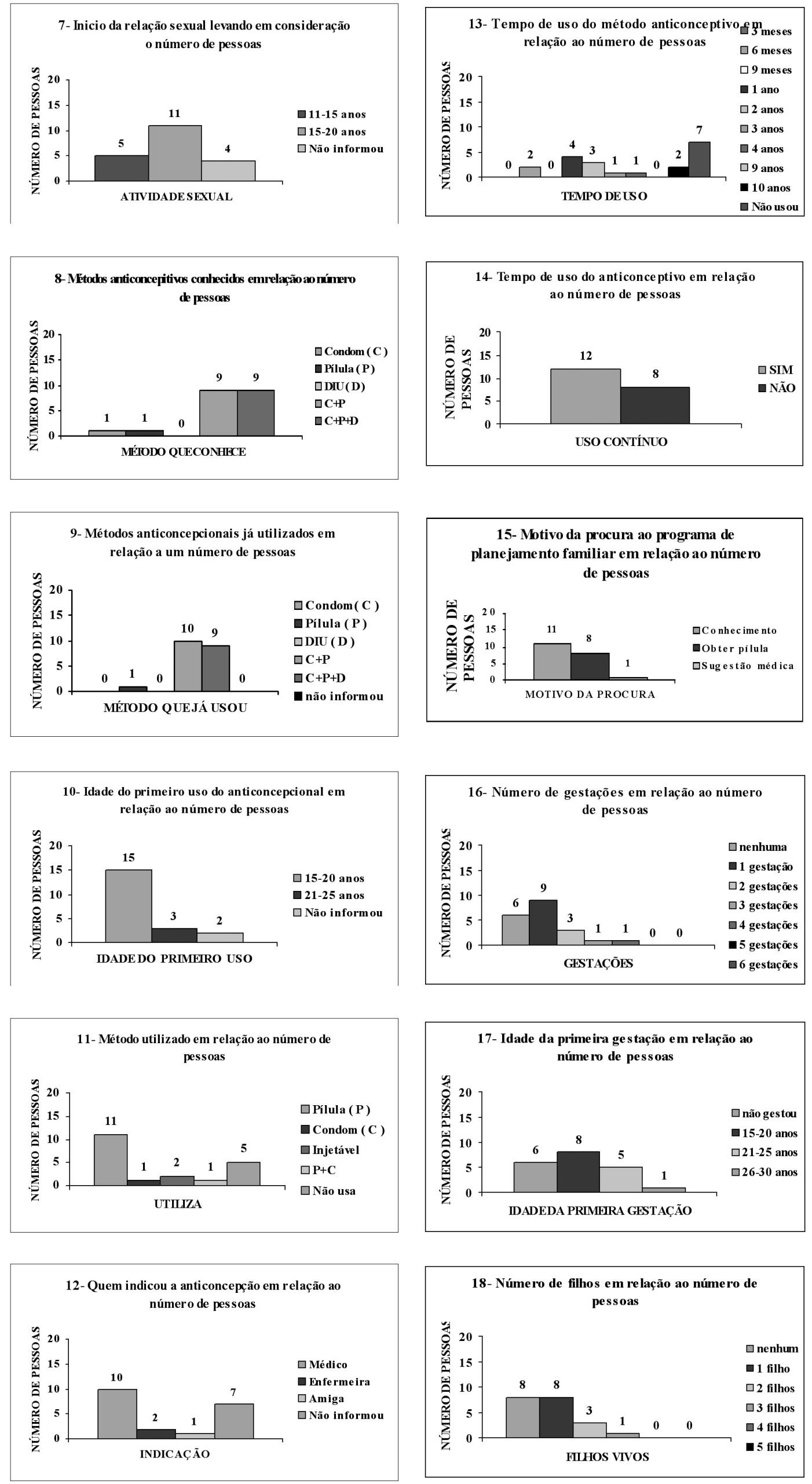

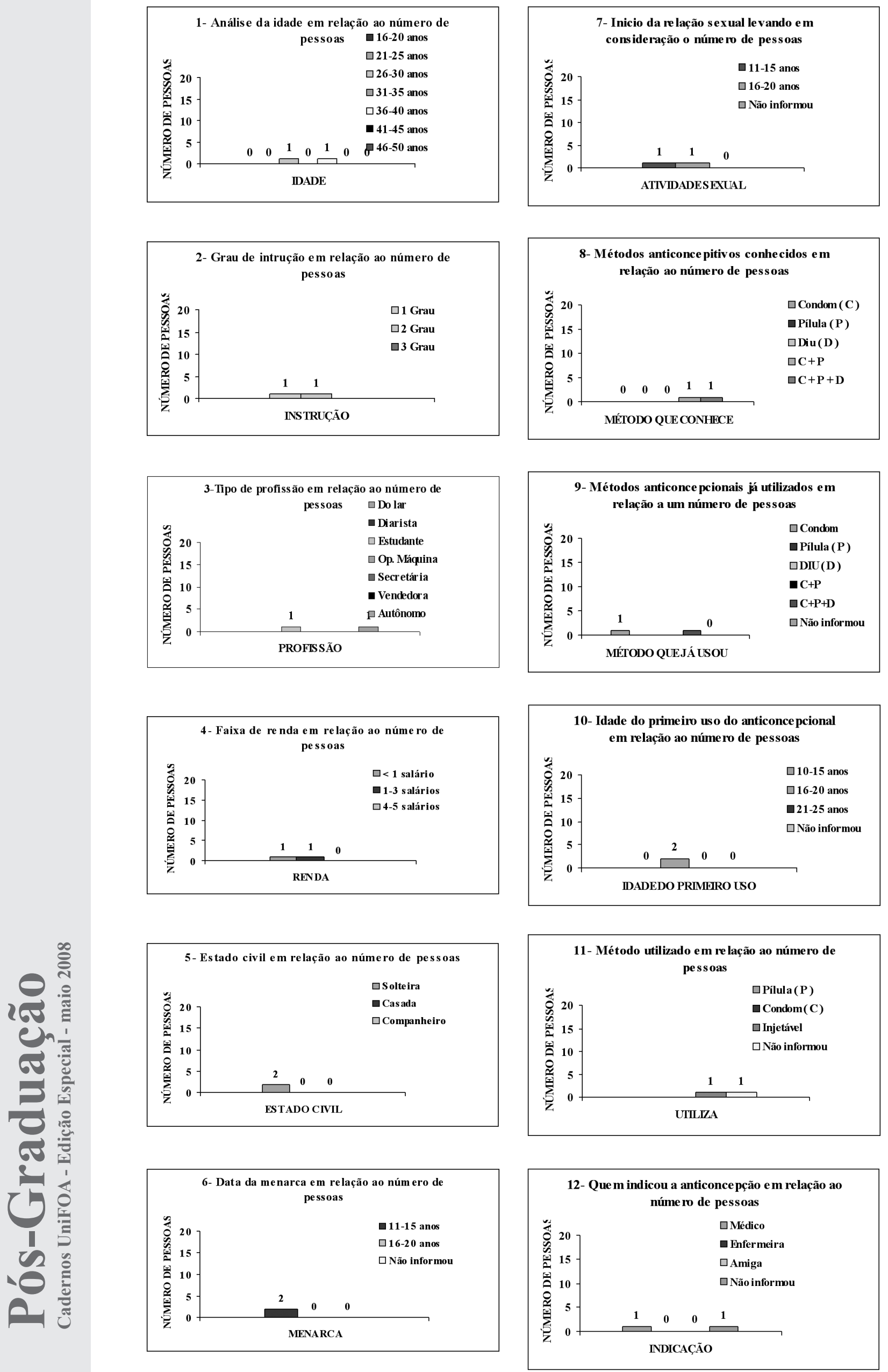

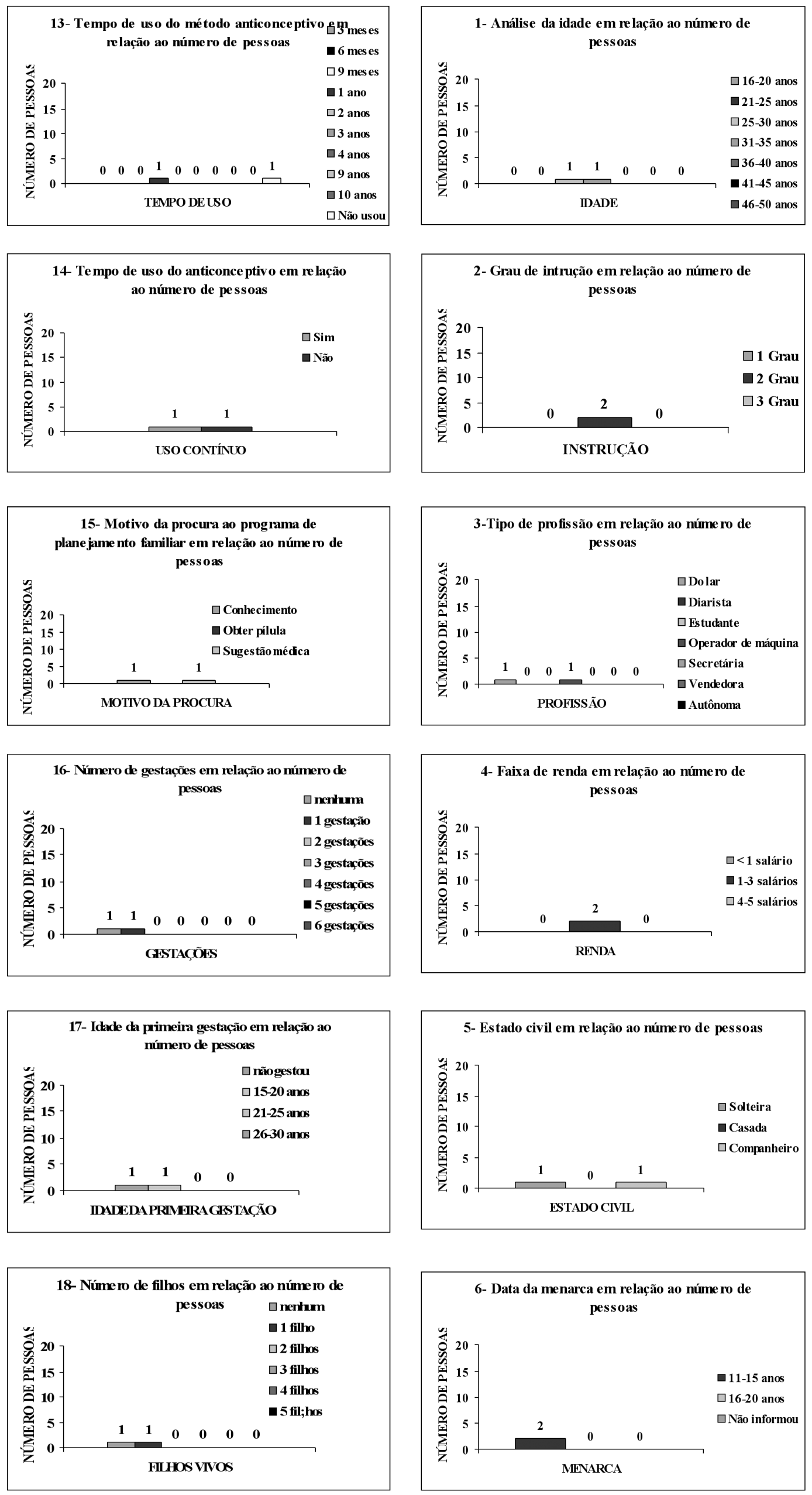

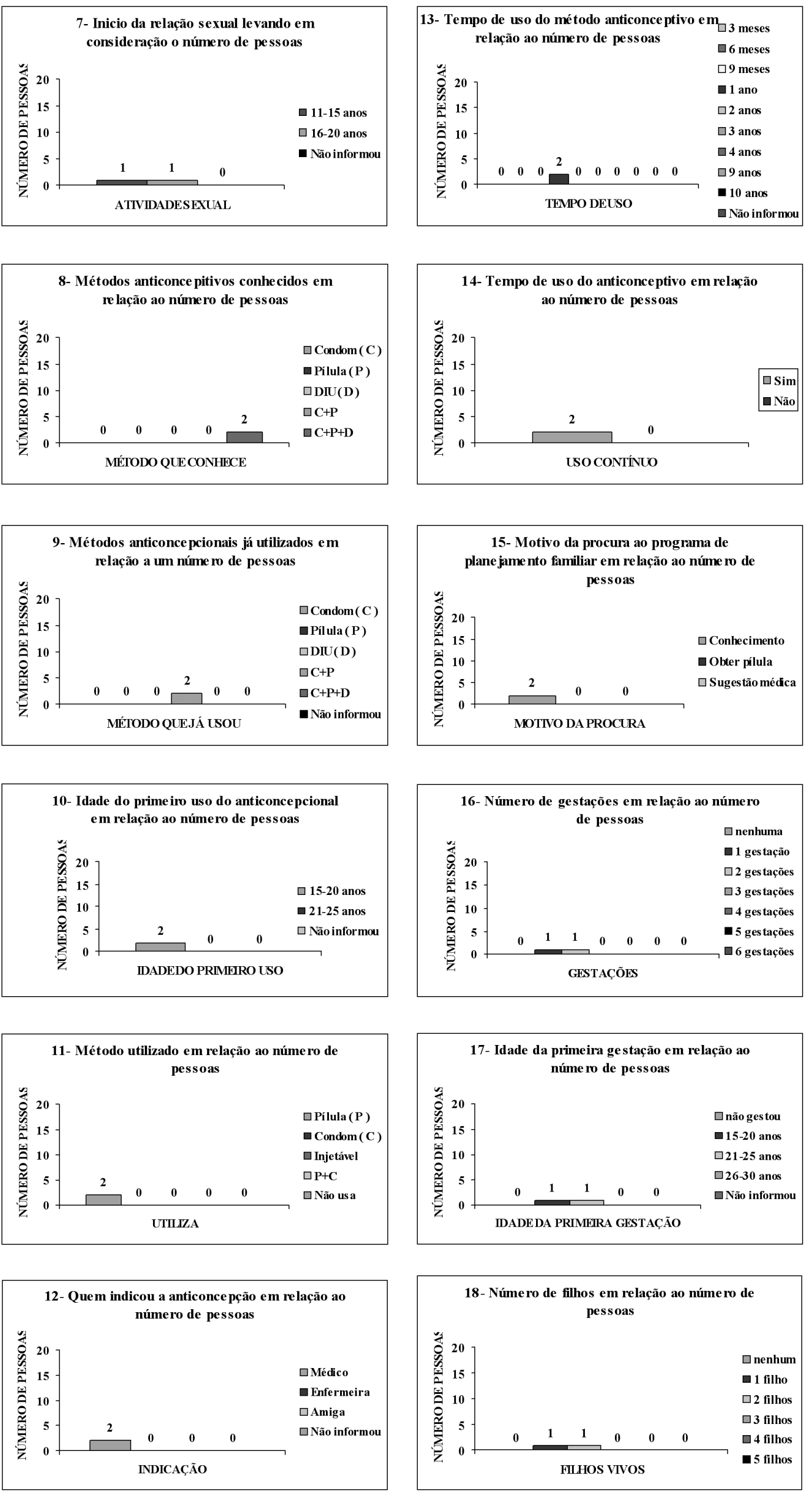
A laqueadura foi feita por 10 mulheres (Gráfico E-1), a maioria acima de 25 anos e com mais de 2 filhos (Gráfico E-18). O grau de instrução é baixo (Gráfico E-2), e a maioria dona de casa (Gráfico E-3). Esta população tem faixa de renda entre 1 à 3 salários mínimos (Gráfico E-4), 80\% deste grupo tem parceiro fixo (Gráfico E-5), todas têm conhecimento de outros métodos anticoncepcionais e 70\% destas mulheres deve filho antes dos 20 anos (Gráfico E-17). Todas foram procurar este serviço específico onde $90 \%$ já usou pílula e condom masculino (Gráfico E-11). No entanto, no Brasil, o planejamento familiar, destacando a laqueadura por ser um método radical, tem amparo na constituição federal e é regulamentado pelas leis específicas referentes aos direitos reprodutivo (TAVARES, LEITE, TELLES, 2007).

A anticoncepção injetável obteve baixa procura. Estas mulheres apresentem dados muito parecidos, onde ambas têm parceiro fixo (Gráfico D-5), renda entre 1-3 salários mínimos (Gráfico D-4) e conhecem e já fizeram uso de outro método anticoncepcional, não usam camisinha (Gráfico D-11) e são mães (Gráfico D18). A pílula anticoncepcional é o método mais popular usado, sendo $70 \%$ com renda entre 1 à 3 salários mínimos (Gráfico F-4) e 50\% são donas de casa (Gráfico F-3), 70\% começaram a usar pílula cedo (Gráfico F-10) e 80\% fazem uso contínuo (Gráfico F-14) e já tem no mínimo um filho, 70\% tem parceiro fixo (Gráfico F-5) e a maioria desta população se encontra entre os 16 e 25 anos e idade. Um dado comum a todos os grupos é que a orientação médica e a principal indicação de qualquer método.

Os dados referentes sobre a vasectomia nos mostraram que a idade dos que aderem ao método é composta de adultos jovens, sendo a grande maioria acima dos 25 anos, chegando até aos 50 (Gráfico G-1). O grau de instrução é baixo, a maioria tendo apenas o primeiro grau (Gráfico G-2), e por conseguinte, as profissões são de mão-de-obra pouco qualificada, acarretando em uma renda de 1 à 3 salários-mínimos para $80 \%$ dos pesquisados (Gráfico G-4).

A forte concentração na pílula, condom masculino e na esterilização, como métodos contraceptivos, somada à discrepância existente entre a preferência e o comportamen- to reprodutivo pode ser atribuída, em grande parte, à ausência de um programa de planejamento familiar que sustente essa demanda total por métodos anticoncepcionais, isto é, das mulheres usuárias de métodos contraceptivos e daquelas com necessidade insatisfeita por anticoncepção.

A grande maioria é composta de casais que tem uma parceira fixa e por homens acima de 25 anos com 3 ou mais filhos no universo de $80 \%$ dos pesquisados (Gráfico G-18). A primeira relação sexual de todos os pesquisados começou antes dos 20 anos, sendo que $40 \%$ dos pesquisados começaram antes dos 15 anos (Gráfico G-7).

O grau de conhecimento de outros métodos anticoncepcionais além da vasectomia e do condom masculino chega a $60 \%$ dos pesquisados, enquanto os $40 \%$ restantes só conhecem o condom masculino como alternativa para anticoncepção (Gráfico G-8). A idade do primeiro uso de algum método anticoncepcional por parte dos pesquisados começou na faixa dos 16 aos 20 anos para $40 \%$ dos pesquisados, enquanto que $60 \%$ dos pesquisados não informaram ou não sabiam (Gráfico G-10). O método anticoncepcional da vasectomia teve a clínica médica como a indicação mais relevante (Gráfico G-12). O tempo de uso de outros métodos anticoncepcionais é muito baixo sendo que a maioria , $80 \%$, só usou de forma contínua por um período de menos de 6 meses (Gráfico G-13).

A transição da fecundidade no Brasil ocorreu com uma rapidez inédita, chegando a níveis inesperadamente baixos - 2,5 filhos por mulher em 1996 (IBGE, 2008). Esse fenômeno tem sido qualificado de rápido, abrupto, intrigante, inesperado, imprevisto, iníquo e perverso. O mais intrigante ainda é o fato de a mulher brasileira lidar com a reprodução em um cenário de escassa ou quase nula participação masculina. Tal assertiva pode ser verificada através dos dados estatísticos da Pesquisa Nacional sobre Demografia e Saúde, que mostra a seguinte prevalência dos métodos contraceptivos mais usados entre homens unidos, incluindo suas parceiras: esterilização feminina $40,3 \%$; pílula anticoncepcional 18,7\%; condom 5,2\% e vasectomia 2,4\% (BEMFAM,1999).

(1)

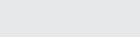



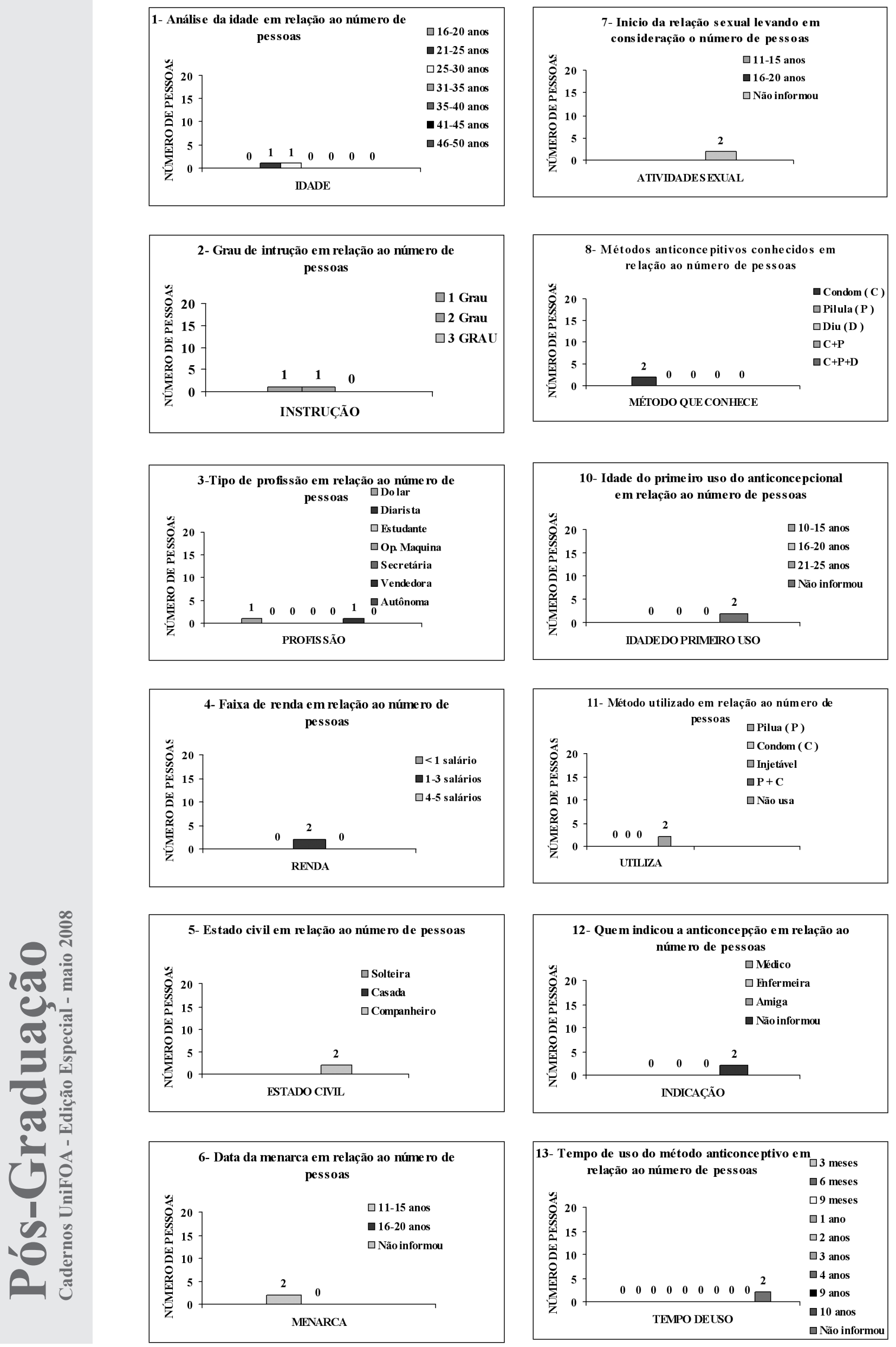

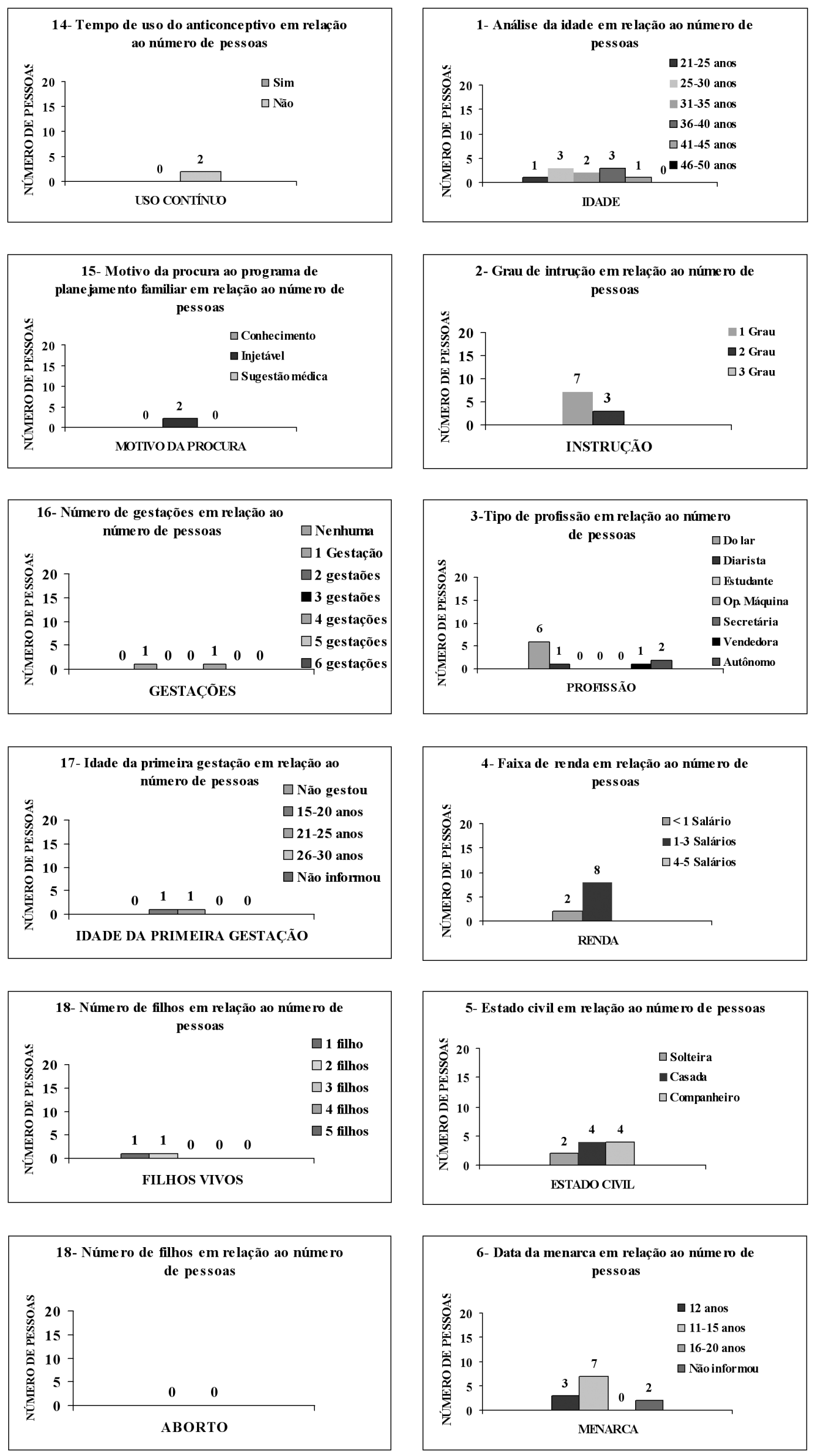

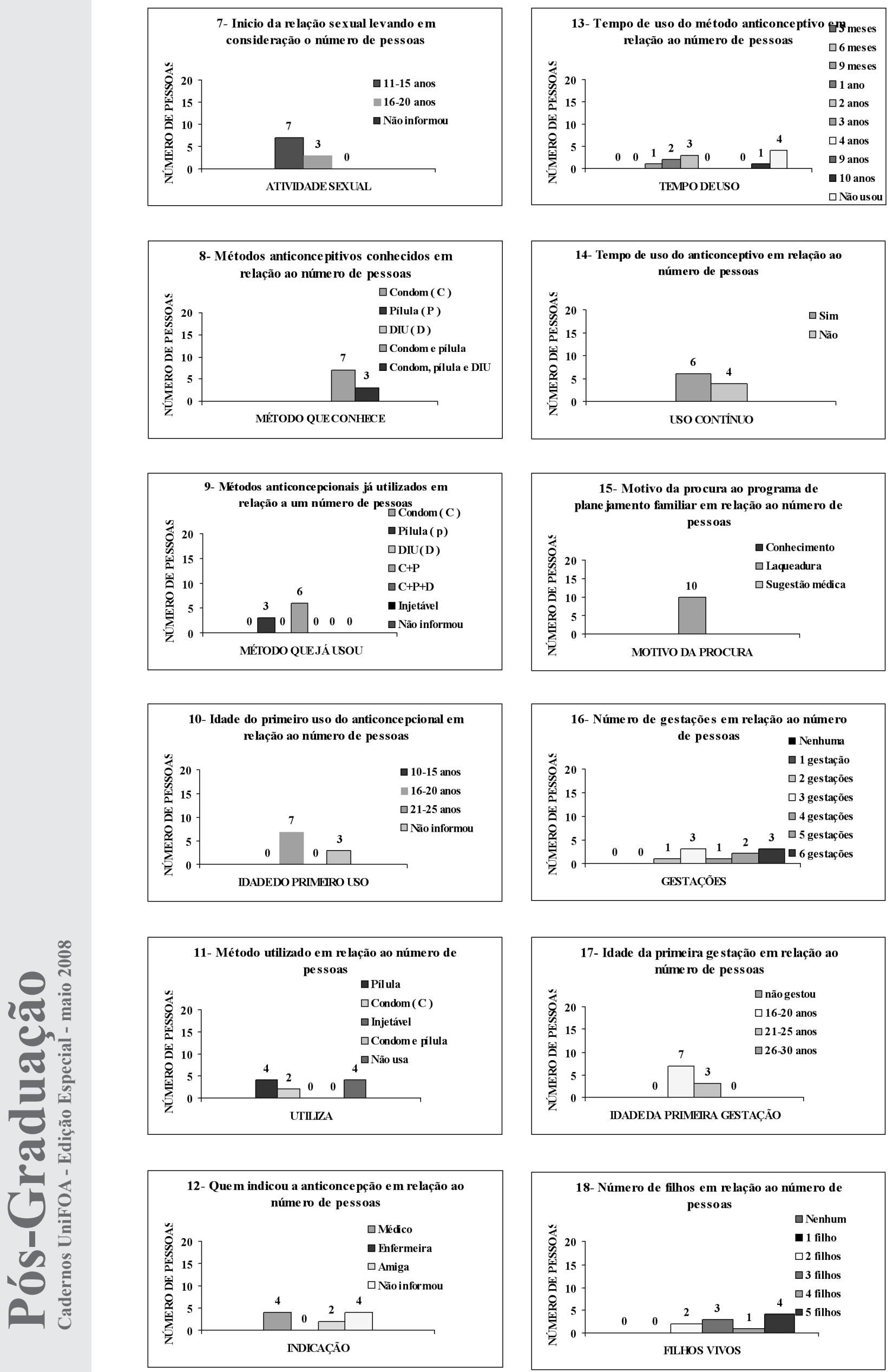

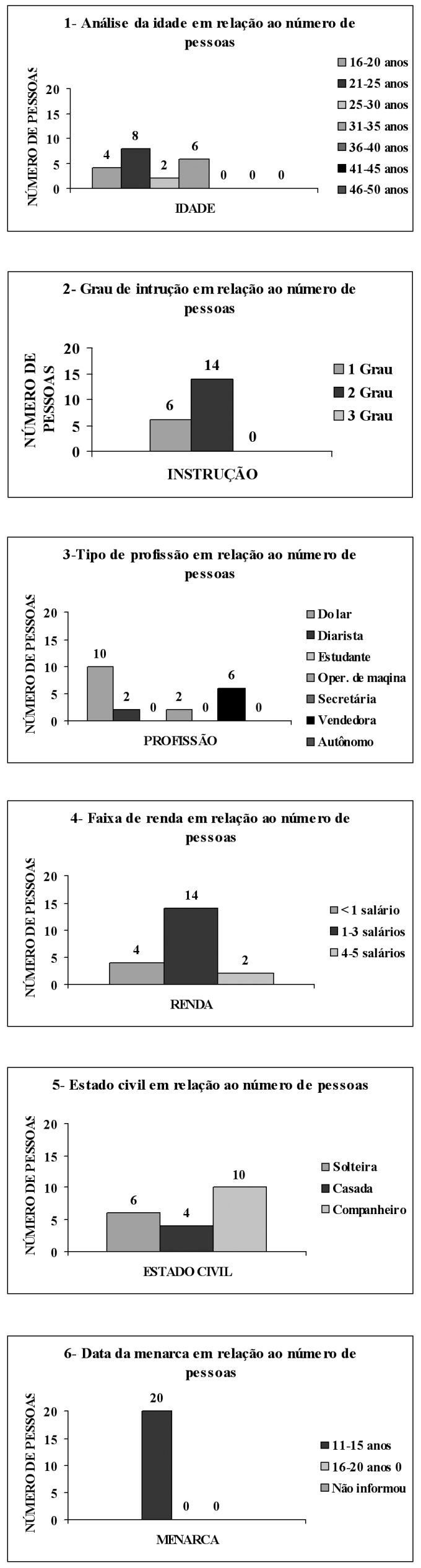
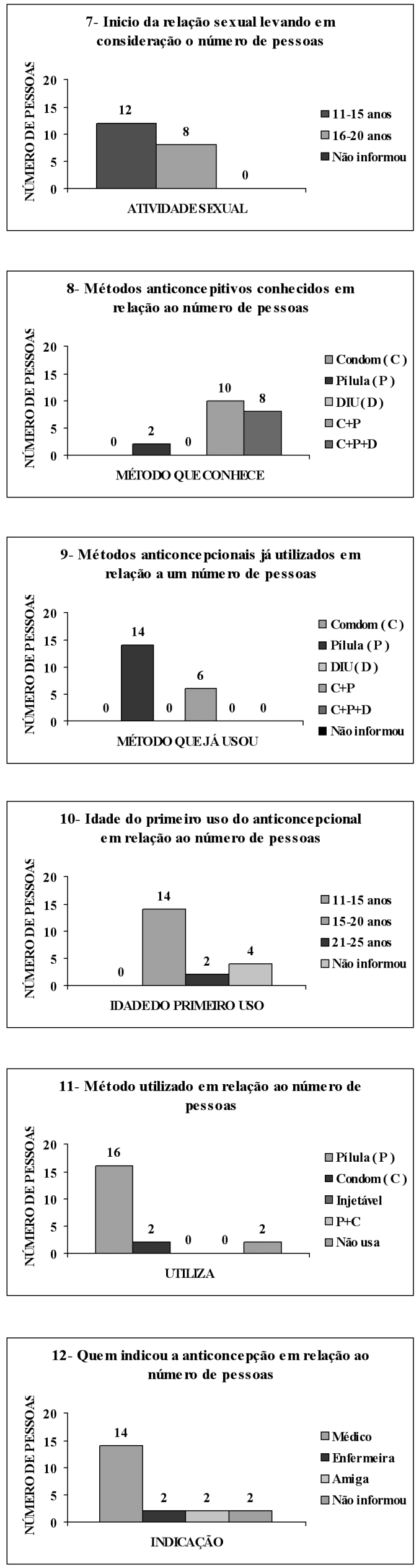

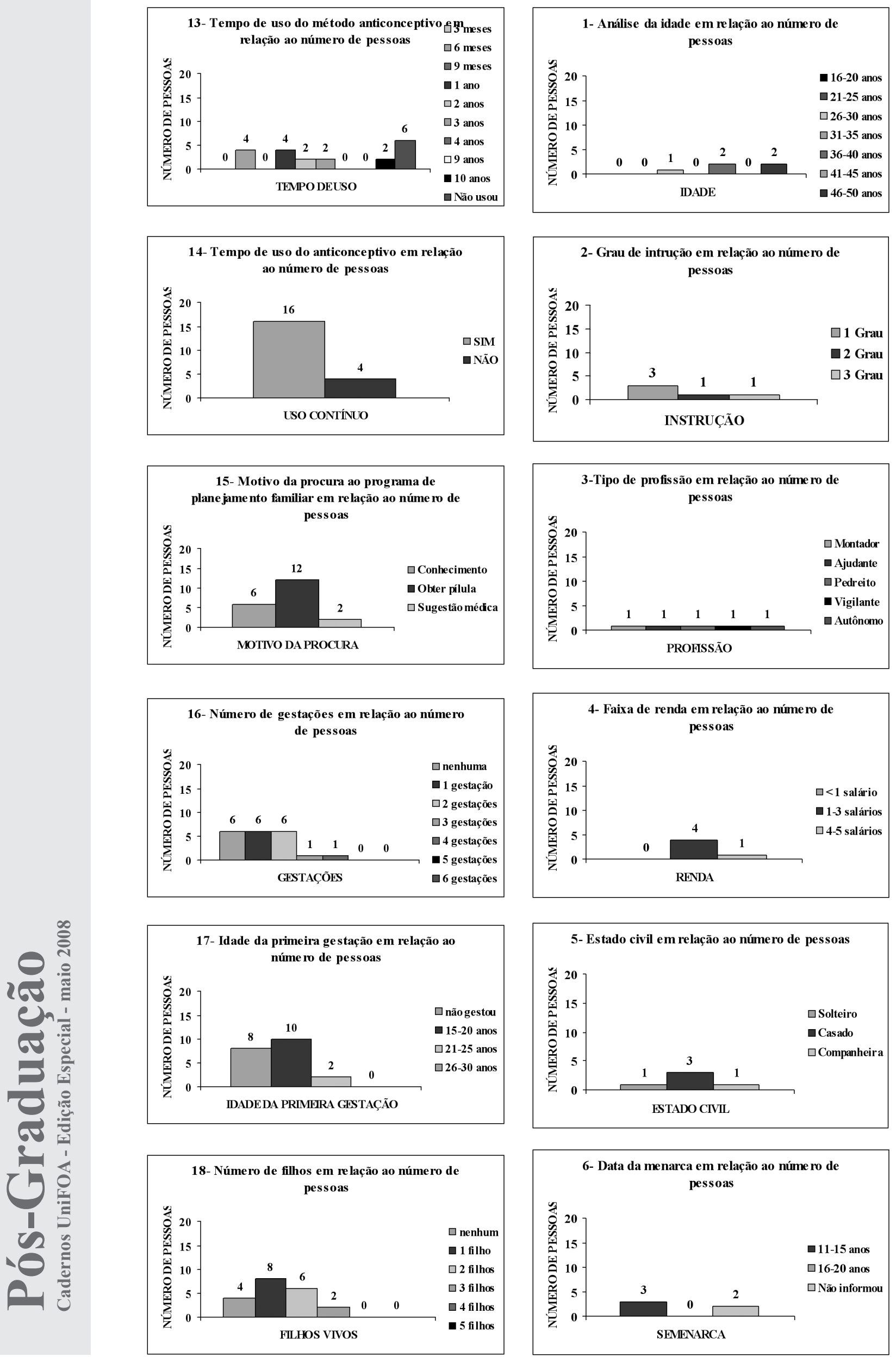

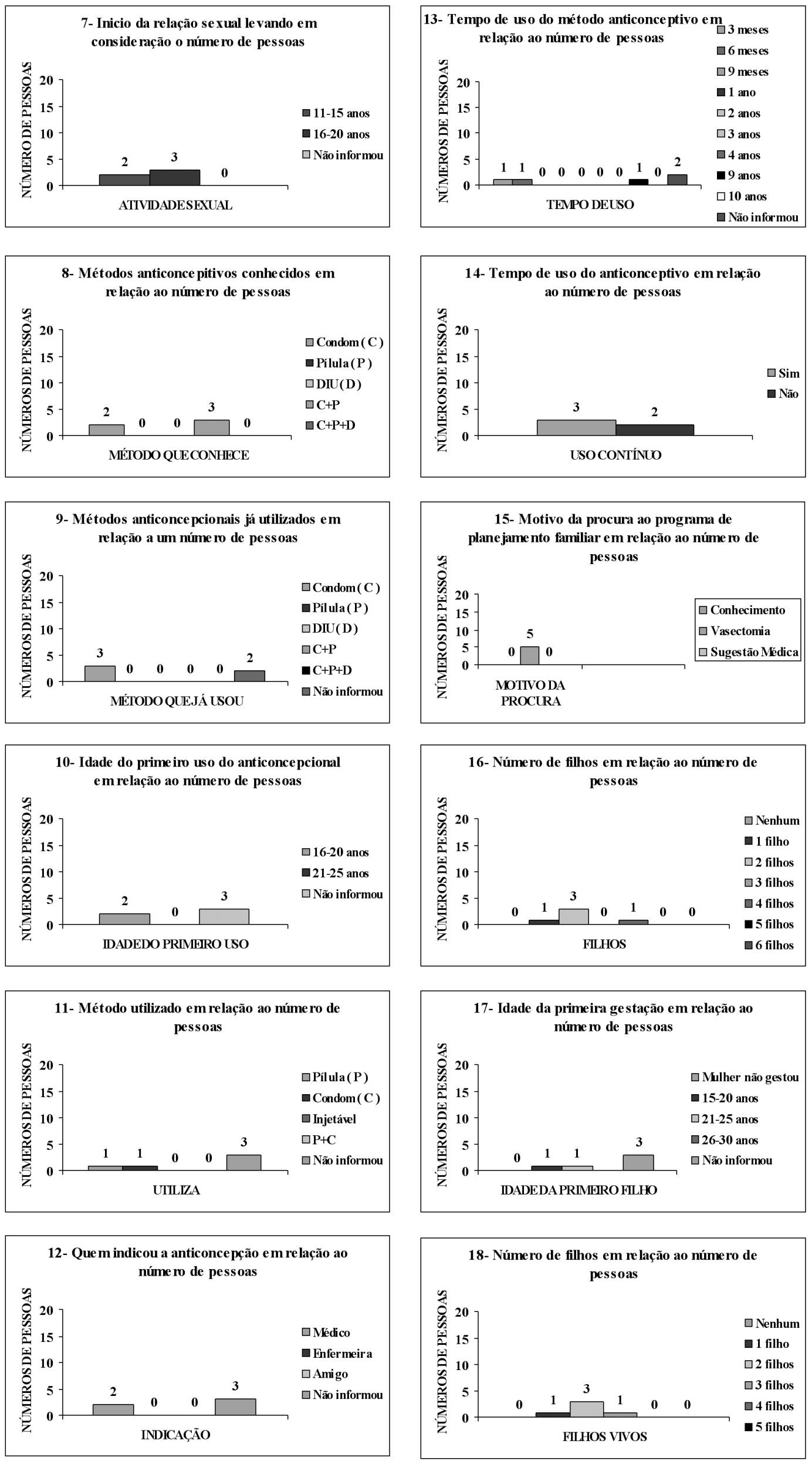
O planejamento familiar deve garantir à população um ambiente humanizado que facilite a reflexão sobre as preferências reprodutivas, com disponibilidade de informações e acesso facilitado aos diversos métodos contraceptivos. Este estudo evidencia a vulnerabilidade das mulheres mais pobres que devem se constituir na população-alvo dos programas de atenção à saúde da mulher. A necessidade de contracepção por parte das mulheres e homens pode facilitar a qualificação dos programas de planejamento familiar através da identificação das principais barreiras no uso de métodos anticoncepcionais para a população em idade reprodutiva que deseja limitar ou espaçar o nascimento dos filhos. O problema da esterilização, como a laqueadura e a vasectomia, demonstra as dificuldades que ambos os sexos enfrentam no controle de sua vida reprodutiva, de um modo geral. No entanto, há uma série de medidas que poderiam e deveriam ser implantadas desde já, a fim de que as restrições que atualmente pesam sobre a liberdade de escolha possam ser minoradas. A análise deste problema evidência que somente a construção de uma sociedade mais justa, igualitária e livre possibilitará a todos o pleno exercício do direito de desejar ou de não ter filhos e agir de acordo com esse desejo.

\section{Agradecimentos:}

Agradecemos em primeiro lugar a Deus; em segundo lugar, a todas as pessoas que de maneira direta ou indireta contribuíram para a elaboração deste trabalho.

\section{Referências}

STEPHAN-SOUZA, A. I. Relendo a Política de Contracepção: O Olhar de um Profissional Sobre o Cotidiano das Unidades Públicas de Saúde. Cad. Saúde Públlca., Rio de Janeiro, II (3): 408-424, 1995.

TAVARES, L.S.; LEITE, I. C.; TELLES, F.S.P. Necessidade insatisfeita por métodos anticoncepcionais no Brasil Rev. Bras. Epidemiol.,.10(2):123-32, 2007.
IBGE - Censo Demográfico 2000 Nupcialidade e fecundidade. Disponível em: URL: http://www.ibge. gov.br Acessado em 15 de janeiro de 2008.

Sociedade Civil Bem-Estar Familiar no Brasil (BEMFAM). Comportamento reprodutivo e Sexual da População Masculina. Rio de Janeiro: BEMFAM, 1999.

SCHIAVO, MR. Síndrome do Machismo e Planejamento Familiar na América Latina. Série de publicações técnicas. Rio de Janeiro (RJ): Sociedade Civil Bem-Estar Familiar no Brasil, nº 11, 1987.

KALCKMANN, S. A. Dinâmica de Uso do Diafragma como Método Contraceptivo entre Usuárias de Serviços Públicos. São Paulo: USP, 1995. Dissertação de Mestrado, Escola Paulista de Medicina, Universidade Federal de São Paulo, São Paulo, 1995.

PERPÉTUO, I.;AGUIRRE, M.A.C. O papel da esterilização feminina nos diferenciais sócio-econômicos do declínio da fecundidade no Brasil. In: Anais do $11^{\circ}$ Encontro Nacional de Estudos Populacionais; 1998; Caxambu. Minas Gerais: ABEP; 1998.

Ministério da Saúde. Assistência em planejamento familiar: manual técnico. 4 ed. Brasília, 2002.

GALASTRO, E.P. Concepção do planejamento familiar na visão dos homens e dos profissionais que vivenciam. Belo Horizonte: UFMG, 1997. Dissertação de Mestrado, Escola de Enfermagem da Universidade Federal de Minas Gerais, Minas Gerais.

LEITE, I.C. Descontinuação de métodos anticoncepcionais no Nordeste do Brasil, 1986-1991. Caderno de Saúde Pública, 19:10005-16, 2003.

WEREBE, MJG. Sexualidade e população, crescimento demográfico e planejamento familiar. Ciência e Cultura, 37(11): 1805-14, 1985.

Área de Saúde do Adolescente e do Jovem, Secretaria de Atenção à Saúde, Ministério da Saúde. Marco legal: saúde, um direito de adolescente. Brasília: Ministério da Saúde, 2005.

Informações bibliográficas:

Conforme a NBR 6023:2002 da Associação Brasileira de Normas Técnicas (ABNT), este texto científico publicado em periódico eletrônico deve ser citado da seguinte forma:

NASCIMENTO E SILVA, M.; COSTA JUNIOR, S.; BARREIROS VIANA, M.; GENESTRA, M. S.; CARDoso, M. D. T.. Planejamento Familiar em Três Poços, Volta Redonda, Estado do Rio de Janeiro, Brasil. Cadernos UniFOA, Volta Redonda, ano 3, Edição Especial, maio. 2008. Disponível em: <http://www.unifoa.edu.br/pesquisa/caderno/especiais/pos-graduacao/01/70.pdf > 